\title{
Development of heat-insulating fire-resistant coating for building structures
}

\author{
Vladimir Chukhlanov ${ }^{1}$, Oleg Selivanov ${ }^{1, *}$, Tatyana Trifonova $^{1}$, Marina Ilina $^{1}$ and Natalia \\ Chukhlanova ${ }^{1}$ \\ ${ }^{1}$ Vladimir State University named after A.G. and N.G. Stoletovs, 600000 Vladimir, Russia
}

\begin{abstract}
The study presents the results of the composition development for producing heat-insulating fire-resistant coating for concrete and metal surfaces of various construction facilities. The composition includes binder - siloxane rubber, filler - hollow carbon microspheres, and flame retardant additive - electroplating sludge. Siloxane rubber improves heat-insulating properties of the obtained coating. Hollow carbon microspheres used as fillers in the amount of 20-50 wt.p. decrease heat insulation of the coating. Flame retardant additive in the amount of 10-15 wt.p. provides selfextinction effect to the cured coating. The study demonstrates that hollow carbon microspheres characterized by low heat insulation ratio are much more effective as compared to the glass or ceramic microspheres. Besides, they provide high strength and low specific weight due to their valuable physical and chemical properties. Metals hydroxides and oxides contained in the electroplating sludge serve as flame retardants in the polymer heat insulating coating, and effectiveness of their activity is directly proportional to their content in the composition, but the increase of galvanic sludge over $15 \%$ is undesirable, as the composition viscosity increases physical and mechanical properties of polymer coating. The study demonstrates that siloxane resin based composition filled with hollow carbon microspheres and containing flame retardant additive of galvanic sludge facilitates producing comparatively cheap but rather effective construction polymer coatings with good heat-insulating and fire resistant characteristics.
\end{abstract}

\section{Introduction}

Nowadays lots of heat-insulating polymer coating have been developed, which found wide application in protecting concrete and metal surfaces of the building structures against high temperature impact. Polyurethane, epoxy, acrylic, siloxane and other reactive oligomers and polymers are used as polymer binders in such coatings [1-3]. But they as most of polymer materials have one significant disadvantage i.e. their increased flammability, caused by high content of carbon and hydrogen in the polymer resin. In case of direct flame polymer materials maintain their combustion and toxic substances (thermal decomposition and polymer materials oxidation products) are exhausted in to the atmosphere, which are

*Corresponding author: selivanov6003@mail.ru 
hazardous for humans and environment. That is why the development of new polymer heat insulating coatings with the increased fire resistance is very actual and important.

The development efficiency of heat-insulating fire-resistant polymer coatings is greatly determined by their physical-chemical properties, which in their turn depend on polymer nature and components composition of the polymer coating (modifiers, fillers, pigments, specialized additives - flame retardants etc.). When developing heat-insulating fire-resistant coatings it is important to use not expensive, not scarce, effective and compatible with the composition components. To improve heat insulating properties of the coating in this research it is suggested to use hollow carbon microspheres as filler. Carbon microspheres are widely used in producing spheroplastics, where hollow microspheres are bound by the polymer binders [4]. They possess a number of valuable physical-chemical properties and in particular low heat-insulation coefficient, which is important for developing heat insulating coatings. Galvanic sludge which is a waste of the chemical treatment of electroplating waste water was suggested to be used as a flame retardant additive for producing fire-resistant coating. Electroplating sludge is applied for producing various construction materials such as ceramic bricks, facade ceramic tiles, protective polymer coatings to construction structures, where it is used as filler or a pigment with the aim of utilizing the sludge [5-8].

The research objective is to study heat-insulating and fire-resistant properties of polymer coating for construction structures, developed on the basis of siloxane resin, filled with carbon microspheres and containing galvanic sludge, serving as a flame retardant additive.

\section{Materials and Methods}

To produce heat-insulating fire-resistant coating, siloxane resin - low molecular weight phenyl-methylsiloxane rubber SKTNF (TU 38.103129-77) - was used as a binder. To solidify the coating, catalyst K-18 - solution of tin diethyl-dicaprylate in ethyl-silicate-32 (YU 6-02805-78) - was used.

Hollow carbon microspheres, obtained by the pyrolysis of phenol-formaldehyde hollow microspheres in argon medium at $12000 \mathrm{C}$ for 4 hours, have been used as filler. The produced microspheres size was from 20 to 100 micron. Besides hollow glass microspheres MS-A9 (YU 6-48-108-94) with spherical particles size of 30-40 micron and hollow ceramic microspheres with particles sized 60-85 micron, obtained by the floatation of flue emissions of thermal power stations, working on solid fuel have been used in the research experiments. The usage of hollow carbon microspheres in the composition provides good strength characteristics of the coating as carbon microspheres have scabrous surface thus increasing physical cohesion between microspheres surface and a binder - siloxane resin. More over different functional groups, which serve as the activation centers in intermolecular chemical interaction with polymer surface matrix can be located on the micropores surface of the carbon microspheres.

The choice of hollow carbon microspheres is also explained by their considerably low heat insulation coefficient in comparison with other hollow microspheres (for instance, ceramic or glass), that is why their introduction into the composition allows obtaining the coating with higher heat-insulation properties. Besides hollow carbon microspheres have less weight in comparison with the other microspheres, thus reducing the coating specific weight and as a consequence to reduce weight load on the construction elements of the treated surfaces.

Electroplating sludge remained after the waste water chemical treatment of the electroplating machine building production in Vladimir was used as a flame retardant additive. For the research electroplating sludge was dried at the temperature of $130{ }^{\circ} \mathrm{C}$ and then subjected to fine grinding using a ball mill up to the grit rate max 40 micron (in compliance with GOST 6589-74). The galvanic sludge comprised the following metal 
hydroxides $\mathrm{Zn}(\mathrm{OH})_{2}, \mathrm{Ni}(\mathrm{OH})_{2}, \mathrm{Cr}(\mathrm{OH})_{3}, \mathrm{Cu}(\mathrm{OH})_{2}, \mathrm{Fe}(\mathrm{OH})_{3}, \mathrm{Ca}(\mathrm{OH})_{2}$ and oxides $\mathrm{CaO}, \mathrm{SiO}_{2}$. Galvanic sludge has been analyzed in $\mathrm{x}$-ray fluorescence spectrometer of sequential analysis "ARLADVANT"X». The elemental composition is presented in the table 1 .

Table 1. Galvanic sludge elemental composition.

\begin{tabular}{|c|c|}
\hline Elements of oxide and hydroxide composition & $\begin{array}{c}\text { Content, } \% \\
\text { (dry) }\end{array}$ \\
\hline $\mathrm{Ca}$ & 42,73 \\
\hline $\mathrm{Cr}$ & 12,89 \\
\hline $\mathrm{Zn}$ & 12,24 \\
\hline $\mathrm{Mg}$ & 6,66 \\
\hline $\mathrm{Si}$ & 6,52 \\
\hline $\mathrm{Fe}$ & 6,17 \\
\hline $\mathrm{Cu}$ & 2,39 \\
\hline $\mathrm{Ni}$ & 1,75 \\
\hline $\mathrm{Al}$ & 1,68 \\
\hline $\mathrm{Mn}$ & 0,098 \\
\hline
\end{tabular}

The addition of electroplating sludge in to the composition as a flame-retardantal low achieving self-extinction effect of the heat-insulating coating, reduced burning time and increased heat resistance without deterioration of such operational characteristics as durability and adhesion.

The samples of heat-insulating fire resistant polymer coating produced for carrying out the research and containing different amount of fillers - hollow carbon microspheres and flame-retardant additive of galvanic sludge, have been tested in compliance with the burning resistance method [10]. Thermal conductivity ratio has been determined in compliance with GOST 23630.2-79 applying the device IT $-\lambda-400$.

\section{Results}

Heat-insulating properties of the developed coating, based on siloxane resin, hollow carbon microspheres and galvanic sludge as filler have been studied at the first stage. Fig.1 demonstrates the coating thermal conductivity coefficient dependence on hollow microspheres content. For the comparison the coating samples have been produced containing different amount of hollow carbon, glass and ceramic microspheres with the binder content of 60 wt. p. and galvanic sludge -10 wt.p.

Fig.1 shows that coatings with ceramic microspheres possess the highest thermal conductivity, followed by the glass microspheres. The coatings containing hollow carbon microspheres are characterized by the lowest thermal conductivity. The effective range of carbon microspheres content in the coating comprises 20-50 weight parts, herewith good heat-insulation properties are provided. At the range over 50 wt.p. thermal conductivity continues to decrease, but the composition viscosity increases, strength reduces and coating adhesion to the covered surface worsens due to the decrease of polymer binder content.

The second stage was devoted to the study of fire resistant properties of the developed coating based on siloxane resin, hollow carbon microspheres and galvanic sludge filler. Galvanic sludge analysis revealed that the high estamount in the content belong stometal hydroxides and oxides like calcium, zinc, chromium, magnesium, silicon, iron. It can be supposed that metal hydroxides and oxides can serve a flame retardant in polymer coatings.

Metal hydroxides are known to decompose into metal oxides and water under the impact of high temperature $\left(180-300{ }^{\circ} \mathrm{C}\right)$. Decomposition reaction is endothermic, which causes polymer matrix cooling up to the temperature below the ignition point. Water formation facilitates combustible gases dilution, discharged during decomposition, weakens reduces the 
oxygen effect and reduces combustion rate. Calcium and silicon oxides present in galvanic sludge as the inert powder contribute to the quenching of the ignited areas of the polymer coating, forming a heat-insulating layer. The efficiency of metals hydroxides, contained in electroplating sludge is directly proportional to their content in the polymer, but the increase of galvanic sludge content over $15 \%$ is undesirable, as composition viscosity is drastically increased and physical-mechanical properties of polymer coating deteriorate.

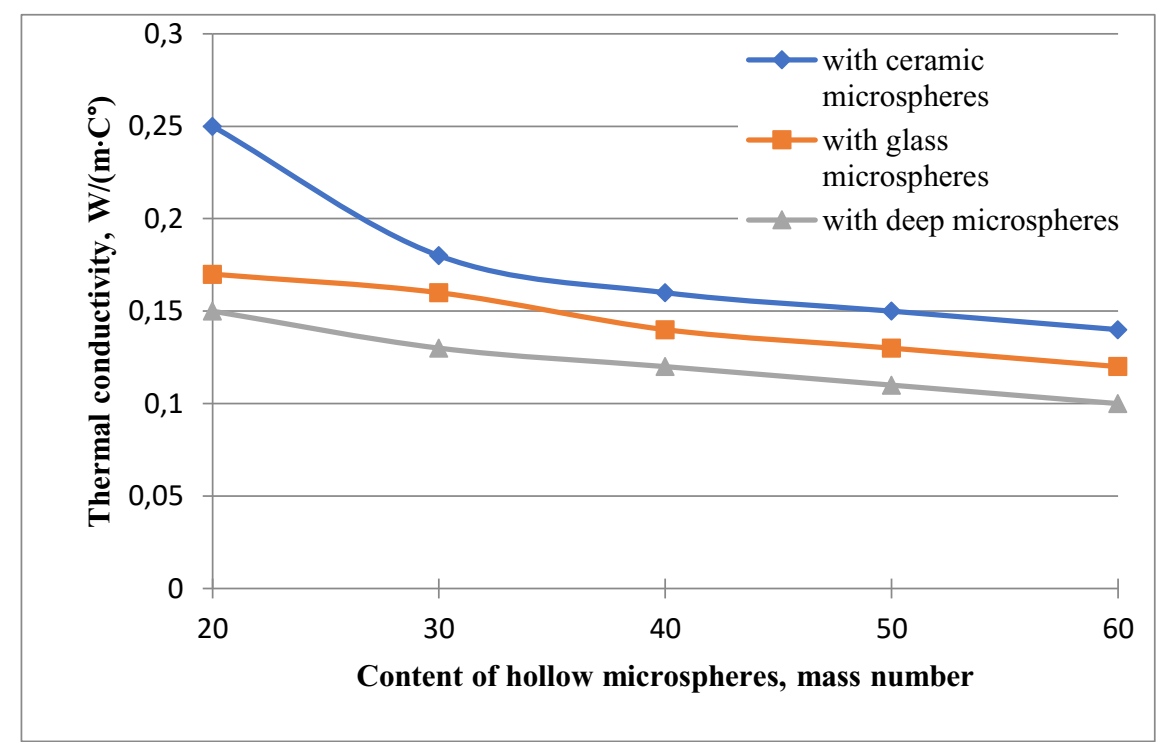

Fig. 1. Dependence of coating thermal conductivity on different type hollow microspheres content.

To test the combustion resistance, the samples of thermal insulation coatings were made from various compositions. Sample compositions are presented in table 2.

Table 2. Samples composition of heat-insulating coatings.

\begin{tabular}{|c|c|c|c|}
\hline Sample № & $\begin{array}{c}\text { Siloxane resin, } \\
\text { wt.p. }\end{array}$ & $\begin{array}{c}\text { Hollow carbon } \\
\text { microspheres, wt.p. }\end{array}$ & $\begin{array}{c}\text { Flame retardant additive }- \\
\text { electroplating sludge, wt.p. }\end{array}$ \\
\hline 1 & 80 & - & - \\
\hline 2 & 80 & 60 & - \\
\hline 3 & 50 & 20 & 5 \\
\hline 4 & 50 & 60 & 5 \\
\hline 5 & 50 & 20 & 10 \\
\hline 6 & 80 & 60 & 15 \\
\hline 7 & 80 & 20 & 15 \\
\hline 8 & 80 & 60 & 25 \\
\hline 9 & 80 & 60 & \\
\hline
\end{tabular}

Combustion resistance test of the obtained samples of thermal insulation coatings was carried out in compliance with GOST 28157-89 (method A). The tests were made with the samples in shape of a bar sized $125 \mathrm{~mm}$ long, $10 \mathrm{~mm}$ wide and 1,5 mm thick marked perpendicular to the axis of the samples at a distance of 25 and $100 \mathrm{~mm}$. The essence of the method is to determine the flame propagation rate along a horizontally fixed sample.

According to method A for the samples $3 \mathrm{~mm}$ thick combustion rate should not exceed $75 \mathrm{~mm} / \mathrm{min}$ between the marks. The experimental tests of all polymer coating samples have been carried out with the measuring flame propagation rate. The test result sarepresented in fig.2. 


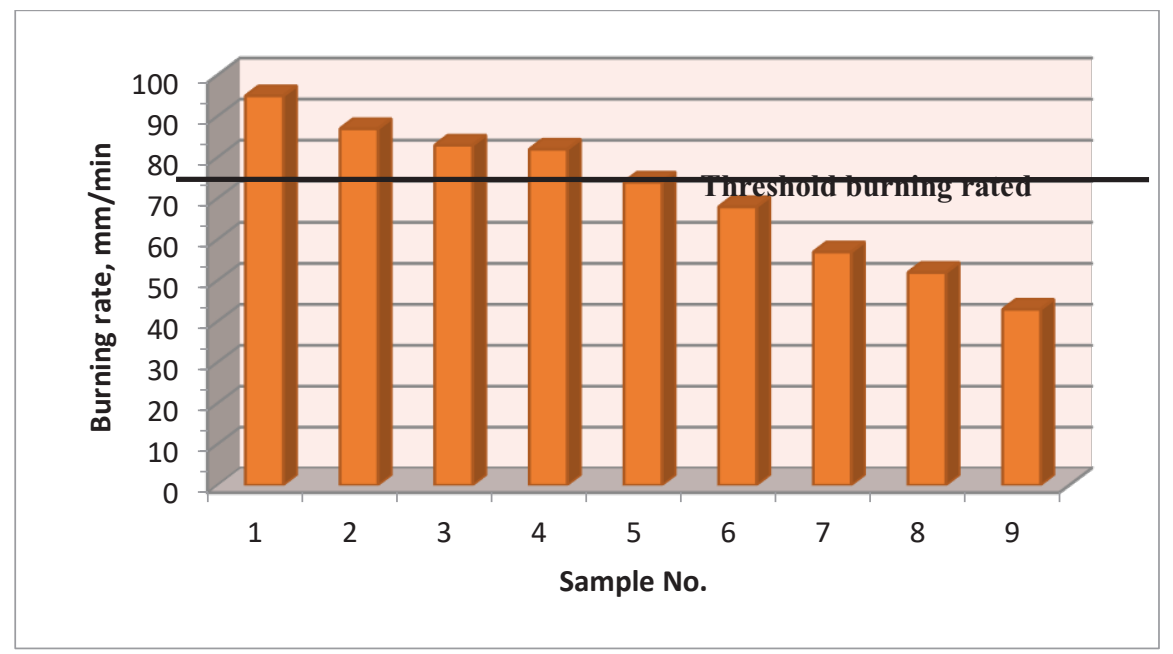

Fig. 2. Dependence of sample combustion rate on the composition of heat-insulating polymer coating.

Test results show that pure cured siloxane rubber (sample№ 1), sample № 2, containing hollow carbon microspheres in addition to the binder, as well as samples №3-4, containing additionally $5 \mathrm{wt}$. p. of galvanic sludge have a combustion rate of more than $70 \mathrm{~mm} / \mathrm{min}$, i.e. practically they are not fire-resistant. Galvanic sludge, used as filler - flame retardant- in the amount of 10-15 wt.p. (samples№ 5-9), causes combustion rate reduction of the coating samples below the threshold level.

It is necessary to high light that though the introduction of electroplating sludge as flame retardant additive in the amount of over 25 wt.p. leads to further combustion rate reduction, but at the same time certain technological problems appear when creating heat-insulating coating due to the drastic increase of polymer composition viscosity. Thus electroplating sludge introduction as flame retardant additive in the amount of 10-15 wt.p. facilitates combustion rate reduction of the samples, proving the previous assumptions, concerning fireresistant mechanism of galvanic sludge, which contains metal hydroxides, calcium and silicon oxides.

It should best ated that technology of producing heat-insulating fire-resistant composition and surfacing treated areas do not provide any difficulties and are done in the following way: hollow carbon microspheres and galvanic sludge are added to siloxane resin and mixed thoroughly. After wards catalyst is introduced into the composition and thoroughly mixed again. The last operation is done directly prior to the surfacing. The composition viability is 6-8 hours at $20^{\circ} \mathrm{C}$.

Before coating the treated surface is well cleaned (mechanical processing and degreasing are carried out). The prepared composition is applied with a brush, spatula, roller or by pouring. It is recommended to carry out operations either indoors or in dry weather. The composition is applied at the temperature from $+10^{\circ} \mathrm{C}$ to $+30^{\circ} \mathrm{C}$, at a relative humidity max $70 \%$.

\section{Conclusions}

The research revealed that the developed coating, filled with hollow carbon microspheres of 20-50 wt.p. is much better in its heat-insulating properties as compared to glass or ceramic microspheres. It is connected with physical-chemical properties of carbon microspheres, providing coating with low thermal conductivity, high streng than low specific density. 
Galvanic sludge application as flame retardant additive in the amount of 10-15 wt.p.in the composition facilitates considerable improvement of the coating fire resistance. Besides it provides self-extinguishing effect, at the same time industrial waste is safely disposed and the price of the composition is reduced.

The use of siloxane rubber binder, filler based on hollow carbon microspheres and galvanic sludge as an flame retardant additive allows obtaining relatively inexpensive, but quite effective structural polymer coatings possessing good thermal insulation and fireresistance.

\section{References}

1. V.Y. Chukhlanov, T.A. Trifonova, O.G. Selivanov, M.E. Ilina, N.V. Chukhlanova, International Journal of Applied Engineering Research 7 (12), 1194-1199 (2017).

2. Tager, A. A. Physical chemistry of polymers (Moscow, Nauchny mir, 2000)

3. D. P. Volkov, Y. P. Zarichnyak, A. A. Marov. Plastic masses, 5-6, 38-41 (2016)

4. V. Yu. Chukhlanov, O.G. Selivanov, Russian Physics Journal 7, 944-948 (2016)

5. I. Vitkalova, A. Torlova, E. Pikalov, O.Selivanov, E3S Web of Conferences 33, 02062 (2018) doi.org/10.1051/e3sconf/20183302062

6. M.A. Sukharnikova, E.S. Pikalov, O.G. Selivanov, É.P. Sysoev, V.Y. Chukhlanov, Glass and Ceramics 73 (3-4), 100-102 (2016)

7. E.S. Pikalov, O.G. Selivanov, V.Y. Chukhlanov, N.V. Chukhlanova, Ecology and industry in Russia 6, 24-29 (2017)

8. A.A. Vorob'eva, V.N. Shakhova, E.S. Pikalov, O.G. Selivanov, É.P Sysoev, V.Y. Chukhlanov, Glass and Ceramics 75 (1-2), 51-54 (2018)

9. Chuklanov V. Yu., Yu. V. Usachev, O. G. Selivanov, L. A. Shirkin, Paintwork materials and their application. 12, 52-55 (2012)

10. Russian State Standard GOST 28157-89 